\title{
The Neurospora mitochondrial tyrosyl-tRNA synthetase is sufficient for group I intron splicing in vitro and uses the carboxy-terminal tRNA-binding domain along with other regions
}

\author{
Joseph D. Kittle Jr., Georg Mohr, ${ }^{1}$ Janet A. Gianelos, He Wang, and Alan M. Lambowitz ${ }^{2}$ \\ Departments of Molecular Genetics and Biochemistry and the Biotechnology Center, The Ohio State University, \\ Columbus, Ohio 43210 USA
}

\begin{abstract}
Neurospora mitochondrial tyrosyl-tRNA synthetase (mt tyrRS), which is encoded by nuclear gene cyt-18, functions in splicing of group I introns in mitochondria. Here, we overproduced functional cyt-18 protein in Escherichia coli and purified it to near homogeneity. The purified protein has splicing and tyrRS activities similar to those of cyt-18 protein isolated from mitochondria and is by itself sufficient to splice the mitochondrial large rRNA intron in vitro. Structure-function relationships in the cyt-18 protein were analyzed by in vitro mutagenesis. We confirmed that a small amino-terminal domain not found in bacterial tyrRSs is required for splicing activity, but not tyrRS activity. Two linker insertion mutations, which disrupt the predicted ATP-binding site, completely inhibit tyrRS activity but leave substantial splicing activity. Finally, deletions or linker insertion mutations in the putative carboxy-terminal tRNA-binding domain inhibit both tyrRS and splicing activities, although some have differential effects on the two activities. Our results show that the normal catalytic activity of the cyt-18 protein is not required for splicing and are consistent with the hypothesis that the protein functions by binding to the precursor RNA and facilitating formation of the correct RNA structure. Regions required for splicing are distributed throughout the cyt-18 protein and overlap, but are not identical to, regions required for tyrRS activity. The finding that the putative carboxy-terminal tRNA-binding domain is required for both tyrRS and splicing activities suggests that the mechanism for binding the intron has similarities to the mechanism for binding tRNA ${ }^{\mathrm{Tyr}}$.
\end{abstract}

[Key Words: RNA splicing; group I intron; RNA catalysis; tyrosyl-tRNA synthetase; aminoacyl-tRNA synthetase; mitochondrial RNA processing]

Received January 24, 1991; revised version accepted March 27, 1991.

The Neurospora mitochondrial tyrosyl-tRNA synthetase ( $\mathrm{mt}$ tyrRS), which is encoded by nuclear gene cyt-18, functions in splicing the large rRNA intron and other group I introns in Neurospora mitochondria (Akins and Lambowitz 1987; Majumder et al. 1989). As discussed elsewhere, the most likely hypothesis is that proteinassisted splicing of group I introns remains RNA catalyzed and proteins function primarily to facilitate correct folding of the intron RNA (Garriga and Lambowitz 1984; Lambowitz and Perlman 1990). Because the cyt-18 protein is an aminoacyl-tRNA synthetase, we suggested that it might bind to the intron RNA via recognition of a sequence or structure that resembles the aminoacylation substrate tRNA ${ }^{\text {Tyr }}$ (Akins and Lambowitz 1987).

${ }^{1}$ On leave from Lehrstuhl für Allgemeine Botanik, Ruhr University of Bochum, Germany.

${ }^{2}$ Corresponding author.
To investigate in more detail the involvement of tyrRS in splicing, we carried out biochemical analysis of the tyrRS protein isolated from mitochondria (Majumder et al. 1989). Using antibodies against trpE-cyt-18 fusion proteins, we identified the cyt-18 gene product as a basic protein having a relative molecular mass of $\sim 70 \mathrm{kD}$. We then showed that this $70-\mathrm{kD}$ protein copurified with both tyrRS activity and with a soluble activity that splices the mitochondrial large rRNA intron in vitro. The cyt-18 protein was a major component of relatively pure fractions of splicing activity obtained by different chromatographic procedures, and these fractions had few, if any, other prominent polypeptide bands in common. Gel-filtration experiments also showed that splicing activity is relatively small $(150 \mathrm{kD}$, with activity trailing to low molecular weights), raising the possibility that cyt-18 protein dimers or monomers are sufficient to splice the mitochondrial large rRNA intron in vitro. 
Previously, we characterized two temperature-sensitive mutants in the cyt-18 gene, cyt-18-1 and cyt-18-2 (Mannella et al. 1979). When grown at high temperature $\left(37^{\circ} \mathrm{C}\right)$, these mutants are defective in splicing the mitochondrial large rRNA intron, as well as additional group $I$ introns in mitochondrial mRNAs, and are also deficient in mt tyrRS activity (Mannella et al. 1979; Collins and Lambowitz 1985; Akins and Lambowitz 1987). Both cyt18 mutants have the same missense mutation leading to a single amino acid change in the cyt-18 protein (Gly 127 to Glu|, which is responsible for both the splicing and aminoacylation defects (Cherniack et al. 1990). The mutant $c y t-18$ protein was shown to be present at normal levels in mitochondria of cells grown at $37^{\circ} \mathrm{C}$ but is inactive in both splicing and aminoacylation in vivo. We also isolated intragenic partial revertants of the cyt-18-2 mutant that specifically alleviate the splicing defect, but not the defect in aminoacylation (Cherniack et al. 1990). These partial revertants had secondary amino acid changes clustered at the amino terminus of the cyt-18 protein (amino acids $50-81$ ) in a region of $\sim 60$ amino acids that has no homolog in the Escherichia coli or yeast $\mathrm{mt}$ tyrRSs and may be a recent addition to the cyt-18 protein. A single partial revertant had secondary changes in amino acids 189 and 190, which are located in the nucleotide-binding-fold region downstream of the cyt-18-2 mutation.

In this study, we overproduced functional cyt-18 protein in $E$. coli and used the $E$. coli expression system to analyze structure-function relationships in the cyt-18 protein by in vitro mutagenesis. Our results show that the cyt-18 protein is both necessary and sufficient to splice the mitochondrial large rRNA intron in vitro, and they are consistent with the hypothesis that the cyt-18 protein functions by binding to the precursor RNA and facilitating formation of the correct RNA structure. Regions of the protein required for splicing include a small idiosyncratic domain at the amino terminus and the putative tRNA binding domain toward the carboxyl terminus, which may also function in binding the intron RNA.

\section{Results}

Expression of functional cyt-18 protein in $\mathrm{E}$. coli

Figure 1 (top) shows a map of the Neurospora cyt-18 gene (Akins and Lambowitz 1987; Cherniack et al. 1990). The open reading frame (ORF) encoding the $\mathrm{mt}$ tyrRS has a length of 669 amino acids and is interrupted by a small intron near the amino terminus. The amino terminus of the ORF has the characteristics of a leader sequence required for targeting the protein to mitochondria. Aminoterminal sequencing of the mature cyt-18 protein isolated from mitochondria showed that the amino terminus corresponds to Leu 33 of the ORF. This indicates that the previously inferred initiation codon is correct (Akins and Lambowitz 1987) and that the leader is cleaved after the sequence ArgGly32, which fits the consensus sequence, Arg small amino acid, for a protein processing site in Neurospora mitochondria (von Heijne et al. 1989).

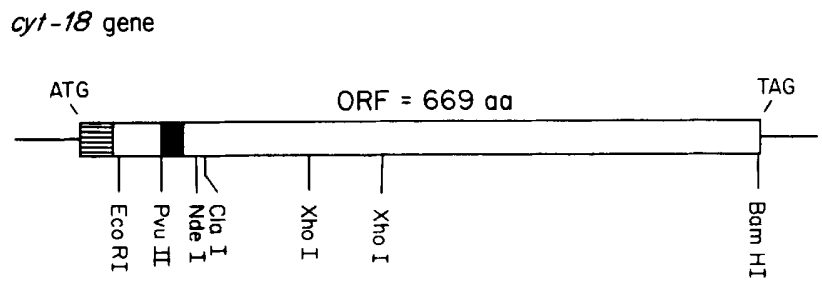

pEX550

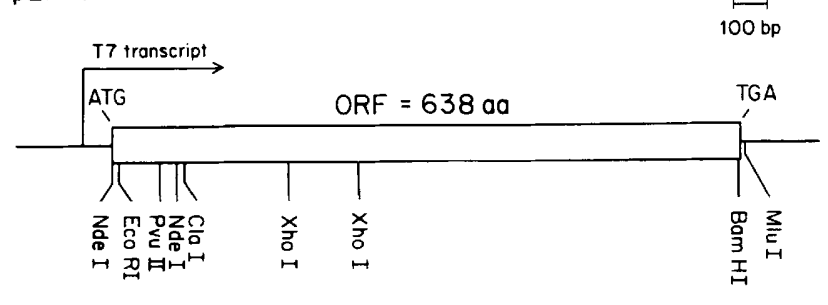

pEX554

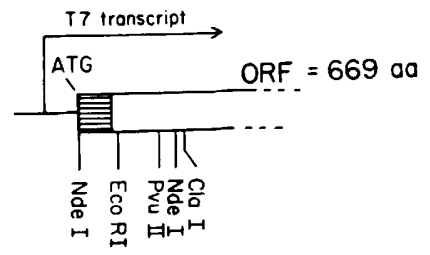

Figure 1. Map of cyt-18 gene and plasmid constructs for expression of cyt-18 protein in E. coli. The cyt-18 gene (top) contains a single 64-bp intron (solid box) and encodes an aminoterminal presequence of 32 amino acids (striped box). The amino terminus of the processed intramitochondrial cyt-18 protein corresponds to Leu33 of the cyt-18 ORF. pEX550 expresses the cyt-18 ORF beginning at Leu33 plus an additional aminoterminal methionine residue. pEX554 is the same as pEX550 but includes the amino-terminal presequence.

The cyt-18 protein was expressed in E. coli, using a T7 expression plasmid pEX501, which was derived from pET3a (see Materials and methods). The primary construct, pEX550, consists of the cyt-18 ORF, from which the intron was removed by site-directed mutagenesis and which has the amino terminus of the mature protein (Leu33) plus an additional amino-terminal Met residue. Other constructs tested in initial experiments were pEX554, which expresses the pre-cyt-18 protein containing the amino-terminal mitochondrial targeting sequence, and pEX511, which has the mature amino terminus (Met-Leu33) but substitutes 18 amino acids encoded by vector sequence for the three carboxy-terminal amino acids. pEX553 has an in-frame deletion of 72 amino acids between the two XhoI sites in Figure 1 and was used as a negative control.

Figure 2A shows that E. coli containing the pEX550 plasmid synthesized the correct-sized protein $(\sim 70 \mathrm{kD}$ compared with the predicted size of $72 \mathrm{kD}$ ), which was readily detected in the Coomassie blue-stained gels. The pEX550 protein was recognized by anti-cyt-18 antibodies in immunoblots and comigrated with authentic cyt-18 protein from mitochondrial ribonucleoprotein (mtRNP) 
(A)

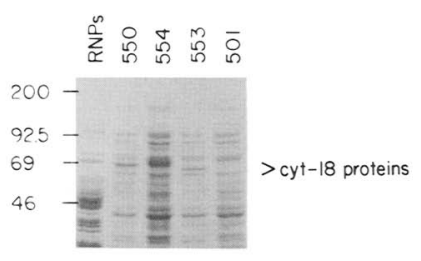

(C)

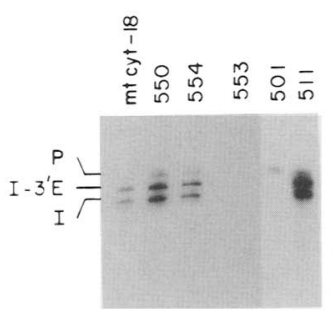

(B)

(D)

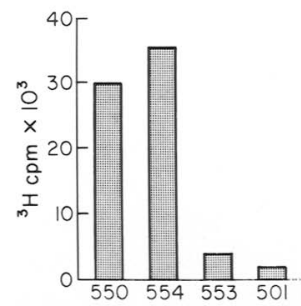

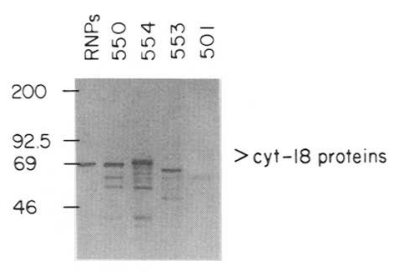

Figure 2. Expression of cyt-18 proteins in E. coli and analysis of splicing and tyrRS activities. $(A)$ Coomassie blue-stained SDS-polyacrylamide gel of proteins in lysates of $E$. coli strains expressing different forms of the cyt-18 protein. Numbers at left show positions of molecular weight markers. $(B)$ Immunoblot of SDS-polyacrylamide gel probed with anti-cyt-18 antibody preparation $\mathrm{C18-2}$. (C) Splicing activity assayed in lysates of $E$. coli strains containing expression plasmids. Lysates for pEX550, pEX554, and pEX553 are the same as those shown in $A$. Splicing was assayed by the $\left[{ }^{32} \mathrm{P} \mid \mathrm{GTP}\right.$ addition method using in vitro transcript from pHX9422, as described in Materials and methods. Some E. coli lysates, including those of cells containing the vector $\mathrm{pEX} 501$, contain a putative end-labeling activity, which results in the appearance of a labeled band at the position of in vitro transcript precursor RNA (P). (D) TyrRS activity assayed in lysates of $E$. coli strain AL565 (DE3), which has a temperaturesensitive defect in tyrRS leading to grossly decreased levels of endogenous tyrRS activity assayed at $37^{\circ} \mathrm{C}$. For the experiment shown, tyrRS activities were normalized for the amount of $c y t$. 18 protein estimated from SDS-polyacrylamide gels stained with Coomassie blue. The following samples are shown: (RNPs) Whole mt RNPs from Neurospora strain cyt-4-1; (mt cyt-18), cyt-18 protein partially purified from $m t$ RNPs by heparinSepharose chromatography; (pEX550) cognate of mature intramitochondrial form of cyt-18 protein; (pEX554) cyt-18 protein containing amino-terminal presequence; (pEX553), cyt-18 protein containing an in-frame deletion of 72 amino acids between XhoI sites shown in Fig. 1; (pEX501) expression vector with no cyt-18 insert; (pEX511) same as pEX550, except that the carboxy-terminal 18 amino acids are different from those of the authentic cyt-18 protein.

preparations (Fig. 2B). Amino-terminal sequencing of the pEX550 protein confirmed that it has the expected amino-terminal sequence. After induction for $1 \mathrm{hr}$, the expressed pEX550 protein constituted from $5 \%$ to $15 \%$ of total E. coli protein and $>50 \%$ of the protein was present in the soluble fraction, as determined by densitometry of Coomassie blue-stained SDS-polyacrylamide gels. The other constructs also gave proteins of the expected size. In several experiments, pEX511, which has the altered carboxy-terminal sequence, gave about twofold more soluble protein than pEX550 (not shown).

The immunoblots (Fig. 2B) show that strains expressing the cyt-18 protein also contained smaller immunoreactive material, which may be due to proteolysis or incorrect translation. Immunoblots for the same $E$. coli strain containing the vector pEX501 and induced with isopropyl- $\beta$ - $D$-thiogalactopyranoside (IPTG) showed no bands at the position of the cyt-18 proteins nor the smaller immunoreactive material, but did show a band of $M_{r} 60 \mathrm{kD}$, which corresponds to an abundant $E$. coli protein that cross-reacts with the secondary antibody used to develop the immunoblots (Fig. 2B).

In initial experiments, the splicing activity of the expressed cyt-18 proteins was assayed directly in $E$. coli lysates, using an in vitro transcript that contains a 583 . nucleotide derivative of the mitochondrial large rRNA intron and flanking exons. Incubation of this transcript with preparations containing splicing activity and $\left[{ }^{32} \mathrm{P}\right]$ GTP results in production of $\left[{ }^{32} \mathrm{P}\right] \mathrm{GTP}$-labeled bands of 584 nucleotides, corresponding to the excised intron, and 634 nucleotides, corresponding to the intron- $3^{\prime}$ exon intermediate resulting from GTP-dependent cleavage at the $5^{\prime}$ splice site. Figure $2 \mathrm{C}$ shows that $E$. coli lysates expressing the pEX550 protein did have splicing activity equivalent to that in mitochondrial RNPs, as did lysates containing the pEX554 protein, which has the aminoterminal leader, and the pEX511 protein, which has the altered carboxyl terminus. In contrast, no splicing activity was detected in lysates of strains containing the vector $\mathrm{pEX} 501$ or the in-frame deletion pEX553. Some $E$. coli lysates, including those from cells transformed with the vector $\mathrm{pEX} 501$, had a putative end-labeling activity that resulted in ${ }^{32} \mathrm{P}$-labeling of the in vitro transcript precursor (Fig. 2C). When present, most of this activity could be separated from the cyt-18 protein by chromatography in DEAE-Sephacel columns (not shown), but residual activity was sometimes found in purified preparations of cyt-18 protein and may be associated with the protein or the intron RNA.

To assay tyrRS activity of the expressed cyt-18 proteins directly in lysates, we used $E$. coli $\mathrm{K} 12$ mutant $565 \mathrm{cN}$. This mutant has a temperature-sensitive defect in its tyrRS so that endogenous tyrRS activity in crude extracts assayed at $37^{\circ} \mathrm{C}$ is decreased at least 50 -fold compared with wild-type $E$. coli strains. The strain was lysogenized with bacteriophage DE3 to support T7 RNA polymerase-driven overexpression of cyt-18 proteins from the constructs described above. As shown in Figure $2 \mathrm{D}$, both the pEX550 and pEX554 proteins have tyrRS activity, which was readily detected in the mutant strain assayed at $37^{\circ} \mathrm{C}$, whereas at least 10 -fold less activity was detected in lysates of cells containing the vector pEX501 or the pEX553 protein with the internal deletion.

Purification of cyt-18 protein from E. coli

The pEX550 protein synthesized in E. coli showed essentially the same chromatographic behavior in DEAE- 
Sephacel and heparin-Sepharose columns as cyt-18 protein isolated from mitochondria (see Majumder et al. 1989). On the basis of initial results, we devised a relatively simple procedure for obtaining substantially pure preparations of the cyt-18 protein from $E$. coli. Lysates were first chromatographed on a medium-scale DEAESephacel column, where the majority of active cyt-18 protein eluted just ahead of the $0.25 \mathrm{M} \mathrm{KCl}$ peak containing the bulk of $E$. coli tyrRS and other proteins loaded on the column. DEAE-Sephacel fractions identified as containing cyt-18 protein by dot blots were pooled, desalted by gel filtration through Sephadex G-75, and chromatographed on a heparin-Sepharose column to remove residual $E$. coli tyrRS activity.

Figure 3 shows results for two different purifications, one for the pEX550 protein and the other for the pEX511 protein, which has a substitution for the three carboxyterminal amino acids. In the experiment shown for pEX550, the DEAE-Sephacel column provided the bulk of the purification, whereas in the experiment for pEX511, the pooled DEAE-Sephacel fractions contained additional proteins, which were removed by heparinSepharose chromatography. In both experiments, the final protein fractions were $\sim 95 \%$ pure, with the major contaminants being two slightly smaller polypeptides that cross-react with anti-cyt-18 antibody. For several different experiments, specific activity measurements

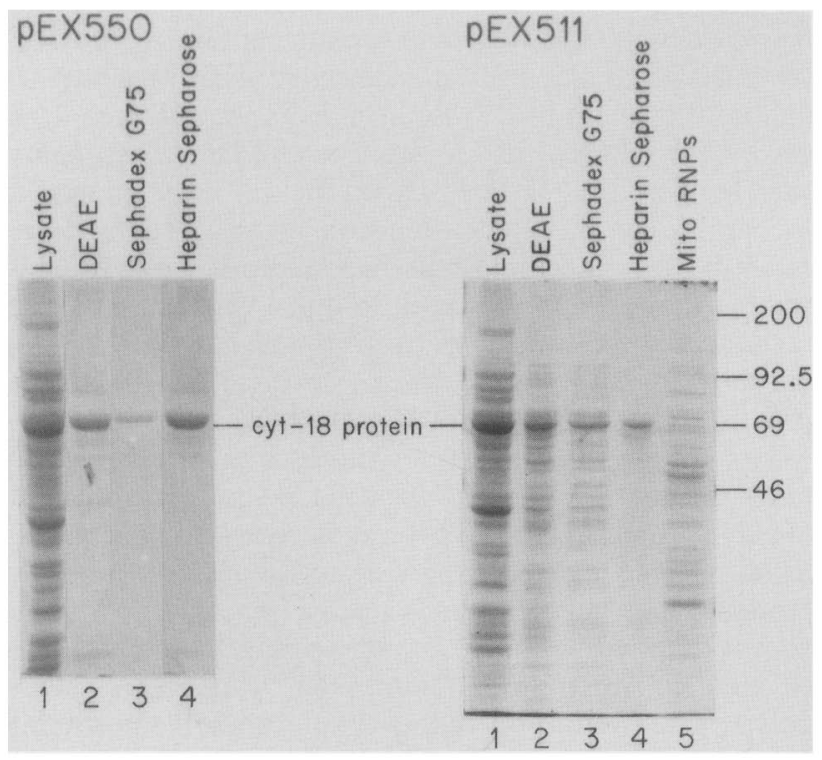

Figure 3. Purification of E. coli-synthesized cyt-18 proteins. pEX550 and pEX511 proteins were synthesized in E. coli and subjected to medium-scale purification through DEAE-Sephacel, Sephadex, and heparin-Sepharose columns, as described in Materials and methods. Fractions at various stages of purification were analyzed by electrophoresis in $10 \%$ SDS-polyacrylamide gels. Shown are gels stained with Coomassie blue. The identity of the cyt-18 protein bands was confirmed by the immunoblotting of parallel lanes (not shown). Proteins from a mt RNP preparation are shown for comparison. showed that the pEX550 protein was purified $\sim 20$-fold with a yield of up to $3 \mathrm{mg}$. The purified protein was highly active in charging tRNA ${ }^{\mathrm{Tyx}}$ and in splicing the mitochondrial large rRNA intron. The specific activity of tyrRS varied from $\sim 100-250 \mathrm{U} / \mathrm{mg}$ of protein, where a unit is 1 nmole of $E$. coli tRNA $^{\text {Tyr }}$ aminoacylated per minute.

\section{Characterization of splicing and tyrRS activity of cyt-18 protein synthesized in $\mathrm{E}$. coli}

The splicing and tyrRS activities of the pEX550 protein synthesized in $E$. coli are similar in all respects to those of authentic cyt-18 protein isolated from mt RNPs. In the aminoacylation reaction, the $E$. coli-synthesized and mitochondrial cyt-18 proteins have $K_{\mathrm{m}}$ values for $E$. coli tRNA $^{\text {Tyr }}$ of $17 \pm 4$ and $25 \pm 6 \mu \mathrm{M}$ and $K_{\mathrm{m}}$ values for ATP of $0.34 \pm 0.04$ and $0.35 \pm 0.05 \mathrm{~mm}$, respectively. The Neurospora mt tyrRS can be distinguished from $E$. coli tyrRS by its sensitivity to GTP, which competitively inhibits the Neurospora enzyme but has no effect on the $E$. coli enzyme (J.D. Kittle Jr. and A.M. Lambowitz, unpubl.). We confirmed that the tyrRS activity of the pEX550 protein was inhibited by GTP, whereas E. coli tyrRS from the same heparin-Sepharose column $(0.25 \mathrm{M}$ $\mathrm{KCl}$ fractions/ was not inhibited.

Splicing reactions with the pEX550 protein had temperature profiles and $\mathrm{Mg}^{2+}$ and $\mathrm{KCl}$ concentration dependencies similar to those of authentic cyt-18 protein (see Garriga and Lambowitz 1986), except that splicing activity of the pEX550 protein appeared to fall off somewhat more rapidly at high $\mathrm{KCl}$ concentrations $1>200$ $\mathrm{mM})$. Splicing reactions carried out with $E$. coli-synthesized or mitochondrial cyt-18 proteins have $K_{\mathrm{m}}$ values for guanosine of $14 \pm 4$ and $17 \pm 4 \mu \mathrm{M}$, respectively, and $K_{\mathrm{m}}$ values for GTP of $91 \pm 10$ and $107 \pm 3 \mu \mathrm{M}$, respectively. The specific activity of the $E$. coli-synthesized pEX550 protein was similar to that of the cyt-18 protein isolated from mitochondria (not shown).

To confirm that the expressed protein carried out exon ligation, we used ${ }^{32} \mathrm{P}$-labeled in vitro transcripts that differ in length of the $3^{\prime}$ exon, so that the ligated exon product could be readily distinguished by gel electrophoresis. As shown in Figure 4, both the mitochondrial cyt18 protein (lanes 1 ) and the $E$. coli synthesized cyt-18 protein (lanes 2) gave the same splicing products having sizes predicted for excised intron and ligated exons. The control (lanes 3) shows that these bands were not detected when ${ }^{32} \mathrm{P}$-labeled precursor RNA was incubated under the same conditions in the absence of protein. Both the E. coli-synthesized and mitochondrial cyt-18 proteins converted $>50 \%$ of the precursor to spliced product in this experiment.

\section{Analysis of the cyt-18 protein by in vitro mutagenesis}

To delineate regions of the $E$. coli protein required for splicing and tyrRS activity, we carried out in vitro mutagenesis, guided by the structural similarity between the cyt-18 protein and the cognate E. coli and Bacillus 


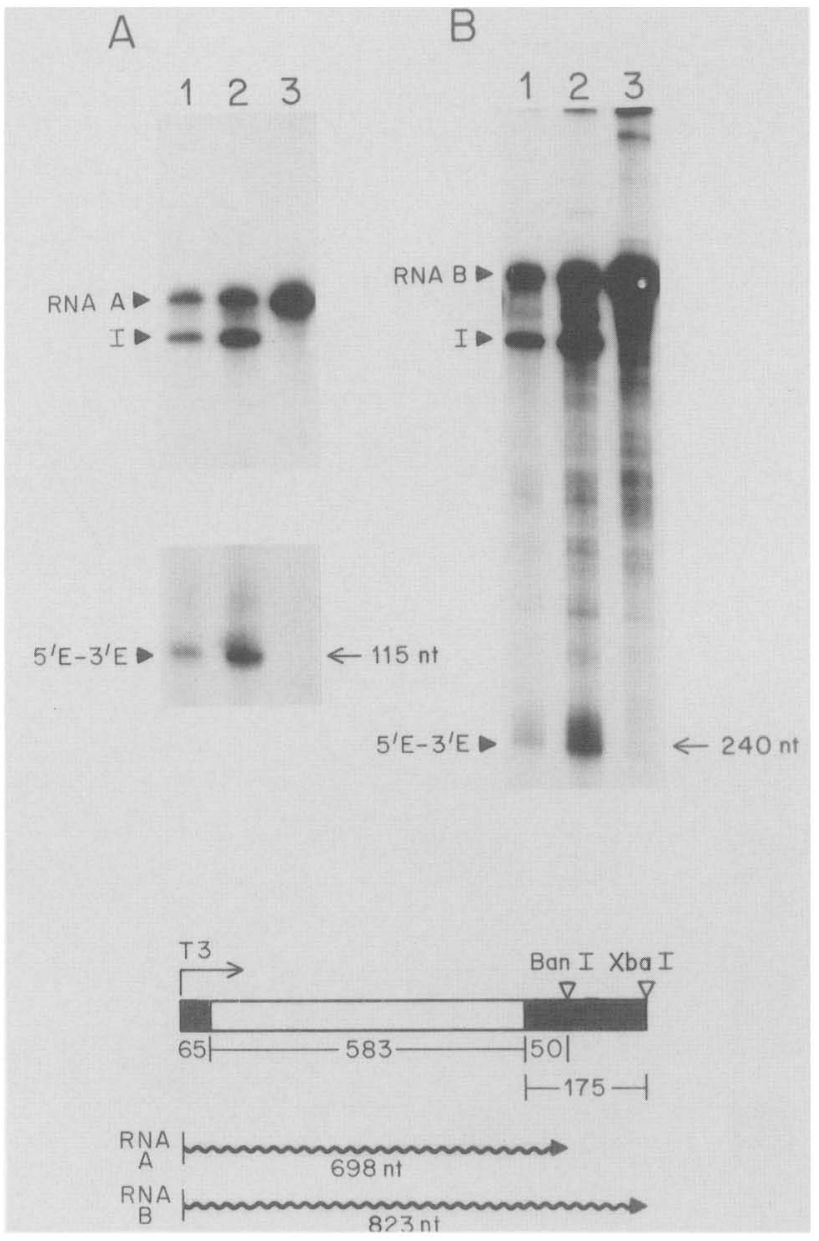

Figure 4. Splicing of ${ }^{32} \mathrm{P}$-labeled in vitro transcript by cyt-18 protein synthesized in $E$. coli or isolated from mitochondria. cyt-18 protein was synthesized in E. coli from plasmid pEX511, and splicing activity was purified as in Fig. 3. Neurospora cyt-18 protein was isolated from mitochondrial RNP preparations by heparin-Sepharose chromatography. Splicing assays were carried out using ${ }^{32} \mathrm{P}$-labeled in vitro transcripts from pHX $9422 \mathrm{cut}$ with Banl or $\mathrm{XbaI}$ to vary the length of the $3^{\prime}$ exon. To detect small bands corresponding to ligated exons, splicing products were analyzed by electrophoresis in $6 \%$ polyacrylamide $/ 8 \mathrm{M}$ urea gels. The intron and spliced exon products are indicated for each transcript length. (Lanes 1) cyt-18 protein purified from $\mathrm{mt}$ RNPs; (lanes 2) pEX511 protein; (lanes 3) no protein added.

stearothermophilus tyrRSs, which are among the beststudied aminoacyl-tRNA synthetases (Schimmel 1987). As shown in Figure 5 (bottom), the Neurospora protein has an amino-terminal mitochondrial targeting sequence and additional domains at the amino and carboxyl termini, which are not present in the bacterial synthetases. The regions of strongest homology to the bacterial synthetases are in the amino-terminal half of the cyt-18 protein and correspond to sequences in the nucleotide binding fold, including the ATP and tyrosine binding sites. In the bacterial tyrRSs, the carboxy-terminal domain downstream of the nucleotide binding fold contains amino acids involved in tRNA recognition (Waye et al. 1983;
Bedoulle and Winter 1986; Schimmel 1987). This region of the cyt-18 protein, downstream of Gly402, is relatively long compared with that of bacterial tyrRSs and has little sequence similarity to the other tyrRSs, except for a stretch of 14 amino acids centered around Arg540, which is conserved at the carboxyl termini of the bacterial tyrRSs and the yeast $\mathrm{mt}$ tyrRS (Fig. 5).

Figure 5 (top) shows the structure of the amino-terminal 318 amino acids of $B$. stearothermophilus tyrRS determined by x-ray crystallography (Brick et al. 1989). Sequences that are highly conserved between the Neurospora $\mathrm{mt}$ tyrRS and the $B$. stearothermophilus tyrRS are spatially arranged near the tyrosyl-adenylation site, for example, the HVGH and QIGG sequences shown in Figure 5. More loosely conserved sequences can be identified in a patch extending across the dimer interface (small diagonal rod at the left in Fig. 5, top). The carboxyterminal region of the $B$. stearothermophilus protein $\{\sim 100$ amino acids) was disordered in protein crystals, preventing determination of its structure.

In this study, mutant derivatives of the cyt-18 protein were synthesized in E. coli and partially purified by small-scale heparin-Sepharose chromatography, which is sufficient to remove the endogenous bacterial tyrRS (see Materials and methods). Heparin-Sepharose column $0.5 \mathrm{M} \mathrm{KCl}$ fractions containing cyt-18 protein were assayed for splicing and tyrRS activity, and cyt-18 protein in the fractions was detected and quantitated by SDSPAGE and immunoblotting. Representative data for mutant proteins are shown in Figure 6, and the data are summarized in Figure 7. Standardization of the assays and methods used for quantitation of splicing and tyrRS activities are described in the legend to Figure 6 . We confirmed that fractions do not contain detectable $E$. coli tyrRS by immunoblotting with anti-E. coli tyrRS antibody (not shown).

The data show that both the pEX550 protein, which lacks the amino-terminal mitochondrial targeting sequence, and the pEX554 protein, which retains this sequence, have similar levels of splicing and tyrRS activity. The pEX550 protein begins with an ATG immediately upstream of Leu33 of the cyt-18 ORF, which corresponds to the amino terminus of mature cyt-18 protein in mitochondria. Immediately following Leu33 is the idiosyncratic domain, which extends from amino acids 34 to 95 and is the site of secondary mutations that restore splicing in partial revertants of the cyt-18-2 mutant. pEX521 gives a mutant cyt-18 protein with a deletion of amino acids 38-80 from this domain. As reported previously, this deletion abolished splicing activity of the cyt-18 protein but had relatively little effect on tyrRS activity (Cherniack et al. 1990). Further characterization here showed that the pEX521 protein and the wild-type pEX550 protein have similar $K_{\mathrm{m}}$ values for ATP $\mid 0.30$ \pm 0.09 and $0.34 \pm 0.04 \mathrm{~mm}$, respectively) and $E$. coli tRNA $^{\text {Tyr }}(21 \pm 4$ and $17 \pm 4 \mu \mathrm{M}$, respectively), indicating that the deletion does not substantially affect the binding of ATP or E. coli tRNA ${ }^{\text {Tyr }}$ by other regions of the cyt-18 protein. In addition to the pEX521 deletion, we analyzed two linker insertion mutations in this region 
Figure 5. X-ray crystal structure of the $B$. stearothermophilus tyrRS and regions of homology between the $N$. crassa mt tyrRS and other tyrRSs. (Top) The structure of the amino-terminal 318 amino acids of the B. stearothermophilus tyrRS protein determined by Brick et al. (1989). Numbers in the structure indicate amino acid positions in the $B$. stearothermophilus tyrRS. The protein dimer interface is adjacent to the thin diagonal rod at the left. Numbers highlighted outside of the structure refer to mutant cyt-18 proteins and are shown close to the inferred position of the mutations, on the basis of amino acid sequence alignment with the B. stearothermophilus tyrRS. (Bottom) Comparison of sequences of the $N$. crassa mt tyrRS (N.c.; cyt-18 protein), Saccharomyces cerevisiae mt tyrRS (S.c.; G. Hill and A. Tzagoloff, unpubl.), and B. stearothermophilus tyrRS (B.s.; Winter et al. 1983). The $m t$ tyrRS proteins from $S$. cerevisiae and $N$. crassa begin with an amino-terminal mitochondrial targeting sequence (striped box). Highly conserved regions are shown in black. Short conserved sequences within highly conserved regions are identified and numbered below. The conserved residue Gly402 marks the end of the last highly conserved region of the cyt-18 protein that has a counterpart in the crystal structure. This residue corresponds to $B$. stearothermophilus Gly308.
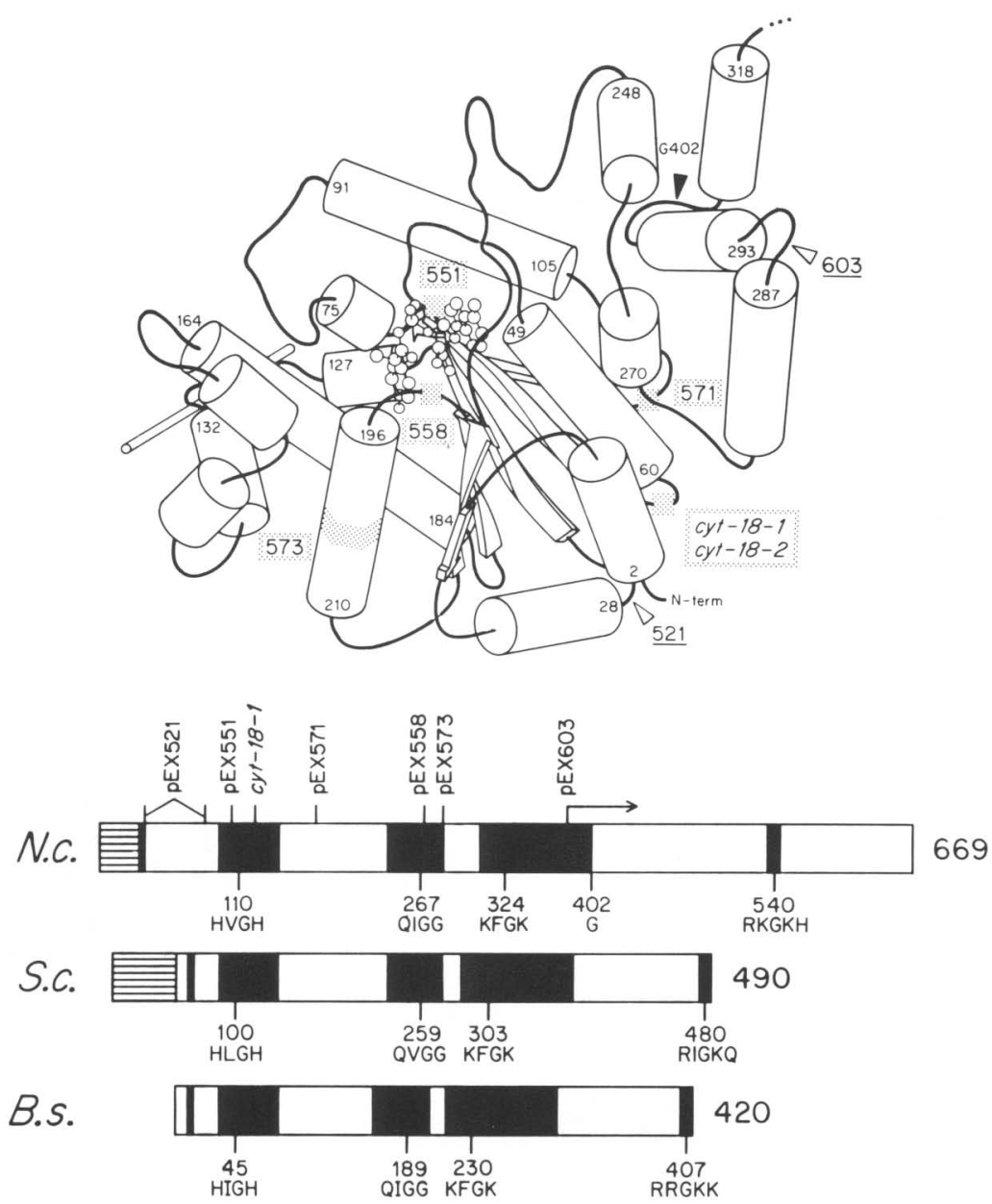

that introduce four extra amino acids after codons 37 and 81 (pEX515 and pEX523). Neither insertion has any detectable effect on splicing activity. The pEX515 insertion retained wild-type levels of tyrRS activity, whereas the pEX523 insertion retained $\geqslant 50 \%$ wild-type tyrRS activity. These two linker insertions are located near either end of the idiosyncratic amino-terminal domain and may demarcate the region required for splicing.

Four mutations (pEX551, pEX558, pEX571, and pEX573) were made in different regions of the nucleotide-binding fold. Assuming that the three-dimensional structure of this conserved region is similar to that of $B$. stearothermophilus tyrRS, the pEX551 and pEX558 proteins would have four extra amino acids inserted in the adenylate-binding cleft in a position that should interfere directly with binding of tyrosyl adenylate (see Fig. 5). As expected from this model, both linker insertions completely inhibited tyrRS activity. However, both retained splicing activity, with the pEX558 protein about as active as wild-type and the pEX551 protein $\sim 25 \%$ as active (corrected for amount of cyt-18 protein; see legend to Fig. 6). These findings suggest that the functional integrity of the ATP-binding site is not required for splicing activity. In contrast, the pEX571 and pEX573 proteins, which have mutations in two other regions of the nucleotide-binding fold, retained essentially wild-type levels of splicing and tyrRS activity. The pEX573 mutation is a 4-amino-acid insertion after Leu281, whereas the pEX571 mutation is a 3-nucleotide deletion, which replaces 2 amino acids, Asp189 and Trp190, with a single Gly residue. We were somewhat surprised to find this latter replacement had no effect on splicing activity, because the 2 amino acids affected in pEX571 are the site of secondary mutations that partially suppressed the splicing defect in the cyt-18-2 mutant (Asp189 and Trp190 changed to Val and Arg, respectively; Cherniack et al. $1990)$.

Analysis of mutant cyt-18 proteins having carboxyterminal truncations showed that the 39 carboxy-terminal amino acids could be removed without inhibiting splicing or tyrRS activity in vitro (pEX533, pEX534). In addition, in the pEX511 protein, replacement of the last 3 amino acids of the authentic cyt-18 protein with 18 amino acids encoded by vector sequence had little, if any, effect on splicing or tyrRS activity. More extensive carboxy-terminal truncations (pEX531, pEX532, pEX602, and pEX603) that extend toward and into the region that would correspond to the tRNA-binding domain of bacterial tyrRSs inhibited both tyrRS and splicing activities. The pEX531 protein, which deletes 116 


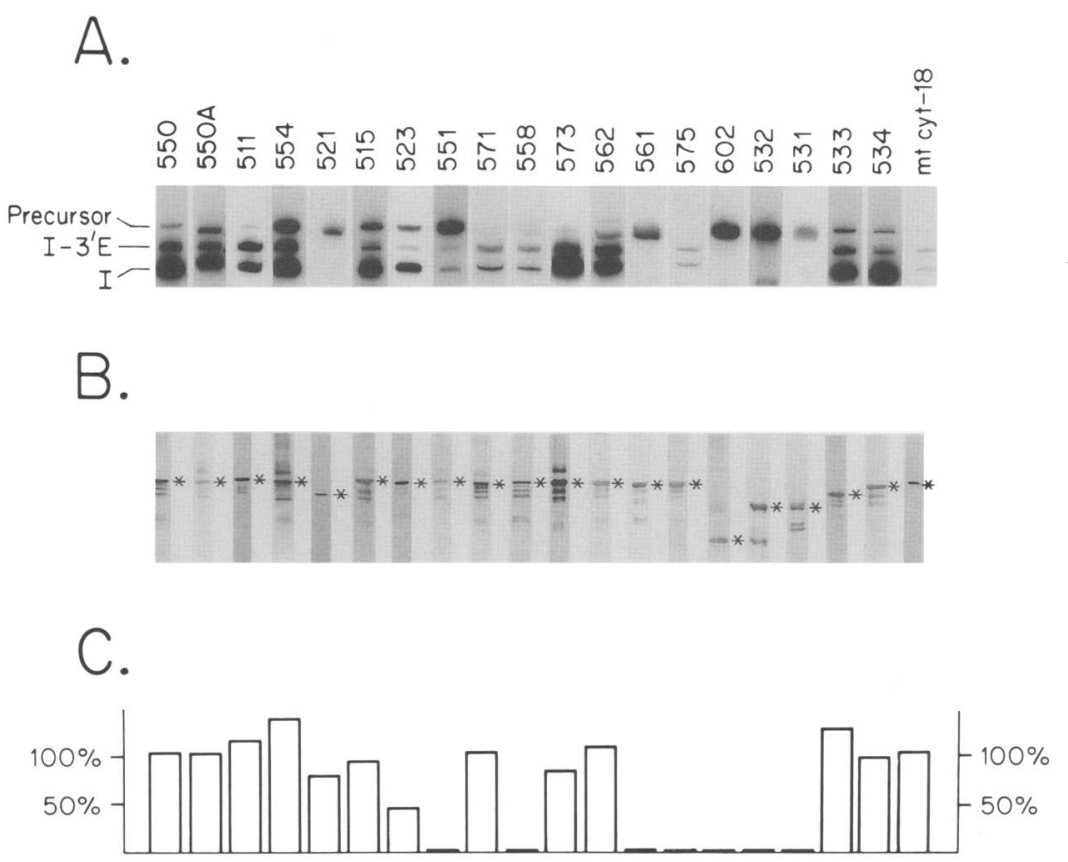

Figure 6. Assays of splicing and tyrRS activities of mutant cyt-18 proteins. cyt-18 proteins were synthesized in $E$. coli and partially purified on small-scale heparin-Sepharose columns. (A) Splicing assayed by the $\left.{ }^{32} \mathrm{P}\right] \mathrm{GTP}$ addition reaction, using in vitro transcript from pHX9422. Some fractions show labeling of in vitro transcript precursor due to putative endlabeling activity discussed in the text. $(B) \mathrm{Im}$ munoblot analysis of fractions used for splicing assays. Immunoblots were probed with anticyt-18 antibodies C18-1 or C18-2, as described in Materials and methods. Asterisks denote cyt18 band. (C) TyrRS activities of the mutant cyt18 proteins. TyrRS activities are expressed as percent of wild-type protein IpEX550 or pEX550A), adjusted for cyt-18 protein concentration estimated by immunoblotting with anti-cyt-18 antibody. Measured counts per minute for active proteins ranged from $6 \times 10^{4}$ to $12 \times 10^{4}$. Background in the tyrRS assays was $\sim 5 \%$ of the counts per minute measured for the wild-type protein and was not subtracted in calculating final percent values. Both splicing and tyrRS reactions were carried out for times established in separate time course experiments as being prior to the plateau in amount of product with the highest concentrations of wild-type protein ( $\mathrm{pEX} 550$ ) used in the assays. For reactions carried out for these times, we verified that both splicing and tyrRS activities increase linearly from 0.05 to $0.4 \mu \mathrm{g}$ of pEX550 protein, encompassing all cyt-18 protein concentrations in the assays. In all cases, splicing and tyrRS activities were assayed across the $0.5 \mathrm{M} \mathrm{KCl}$ peak, which involves a range of protein concentrations. For quantitation, splicing and tyrRS activities of mutant proteins were compared with those of wild-type protein over similar concentration ranges, determined by immunoblots across the $0.5 \mathrm{M} \mathrm{KCl}$ peak and a separate dilution series for each sample. The splicing assays, which are meant to show presence or absence of splicing activity, are those carried out with the highest amounts of mutant cyt-18 proteins; these assays were generally within a factor of two of wild-type protein (pEX550 or pEX550A). Percent values for splicing activity in the text are based on the normalization procedure described above. The data are representative of at least two independent experiments (separate inductions) for each mutant protein.

amino acids, had no detectable tyrRS activity, even at elevated levels of $E$. coli tRNA ${ }^{\text {Tyr }}$ substrate $(30 \mu \mathrm{M})$ but did retain very low, but detectable, splicing activity $1<5 \%$ of wild-type activity; splicing product bands are barely visible in original autoradiogram but too light to be seen in Fig. 6). The pEX532 truncation, which removes an additional 9 amino acids, as well as pEX602, which removes 246 amino acids, had no detectable tyrRS or splicing activities, even with elevated levels of $E$. coli tRNA ${ }^{\text {Tyr }}$ or in vitro transcript substrates $(30 \mu \mathrm{M}$ and 250 $\mu \mathrm{g} / \mathrm{ml}$, respectively). In the case of the largest carboxyterminal truncations, pEX602 and pEX603, we confirmed that the proteins partially purified by heparinSepharose chromatography had high tyrosyl-adenylation activity (Table 1), suggesting that even extensive carboxy-terminal truncations did not substantially alter the conformation of the nucleotide-binding fold in the amino-terminal half of the protein. Some of the carboxyterminal truncations (e.g., 531 and 532) strongly reduced the proportion of expressed protein recovered in the soluble fraction, but the solubilities of the proteins from pEX602 and pEX603, the most radical carboxy-terminal truncations, returned to a high level.

To address the possibility that inhibition of splicing or tyrRS activity is due to gross conformational changes in the carboxy-terminal region, we also analyzed two linker insertion mutations and one single codon deletion in this region (pEX561, pEX562, and pEX575). All of these constructs gave high yields of soluble protein. In pEX562, a 4-amino-acid insertion in an unconserved region of the protein (Tyr417) had no detectable effect on either splicing or tyrRS activity, whereas in pEX561, a 4-amino-acid insertion in another part of the carboxyterminal region (Gly470) resulted in complete loss of both activities, even with high concentrations of RNA substrates described above. Finally, in pEX575, a single amino acid deletion (Asn545) within the short sequence conserved in bacterial and yeast $m t$ tyrRS, gave a protein that lacked tyrRS activity, even at high concentrations of E. coli tRNA ${ }^{\mathrm{Tyr}}$, but had detectable, albeit reduced, splicing activity (5-10\% wild type; Fig. 6$)$.

\section{Discussion}

Here, we show that functional cyt-18 protein can be expressed in large quantities in E. coli. The expressed protein was purified to near homogeneity and shown to have tyrRS and splicing activities similar to those of authentic cyt-18 protein isolated from mitochondria. These findings indicate that the cyt-18 protein is both 
Figure 7. Summary of mutant cyt-18 proteins and their splicing and tyrRS activities. (Top) Map shows Neurospora cyt-18 ORF. Numbers below the map indicate amino acid positions. Regions whose amino acid sequence is highly conserved in E. coli tyrRS are shown in black. The amino-terminal mitochondrial targeting sequence /striped box) extends from amino acid 1 to 32 . (Bottom) Mutant proteins and their tyrRS and splicing activities are summarized. Sites of mutation are indicated by symbols: ( $\mathbf{\nabla}$ ) 4-amino-acid insertion; (O) 1-amino-acid deletion; $(\nabla)$ truncation end point. Linker insertions and 3-base deletions have the following predicted sequence changes: pEX515, $\mathrm{F}_{37} \mathrm{PWEFG}_{38} ;$ pEX523, A $_{81}$ HAWAG $_{82} ;$ pEX551, $\mathrm{I}_{102} \mathrm{AGSGD}_{103} ; \mathrm{pEX} 571, \mathrm{~A}_{188} \mathrm{GA}_{191} ; \mathrm{pEX} 558, \mathrm{D}_{272}$ PHGDQ $_{273} ;$ pEX573， $\mathrm{L}_{281} \mathrm{DPWVE}_{282} ;$ pEX562, $\mathrm{Y}_{417}$ ADPHT $_{418} ;$ pEX561 G $_{470}$ PHGGR $_{471} ;$ pEX575, $\mathrm{H}_{544} \mathrm{~V}_{546}$. Large deletions have the following predicted sequence changes: pEX521, $\mathrm{F}_{37} \mathrm{PWA}_{81}$; pEX553, $L_{209} E_{282}$. Truncated proteins have the following predicted carboxy-terminal sequences: pEX511， P ${ }_{666}$ AANKARKEAELAAATAEQ; pEX $603, \mathrm{D}_{382} ; \mathrm{pEX602}, \mathrm{I}_{423} ; \mathrm{pEX} 532, \mathrm{H}_{544} ; \mathrm{pEX} 531$, $\mathrm{S}_{553} \mathrm{VSG}_{;}$pEX533, $\mathrm{L}_{630} \mathrm{G}_{;}$pEX534, $\mathrm{D}_{665} \mathrm{LSG}$. TyrRS activity of $<5 \%$ of pEX550 activity is considered negative. The sensitivity of detection of splicing is less than $\sim 5 \%$ of the activity of the pEX550 protein. $(+)$ Active; $(-)$ inactive; $( \pm)$ reduced activity; $[(-\|)$ barely detectable activity.
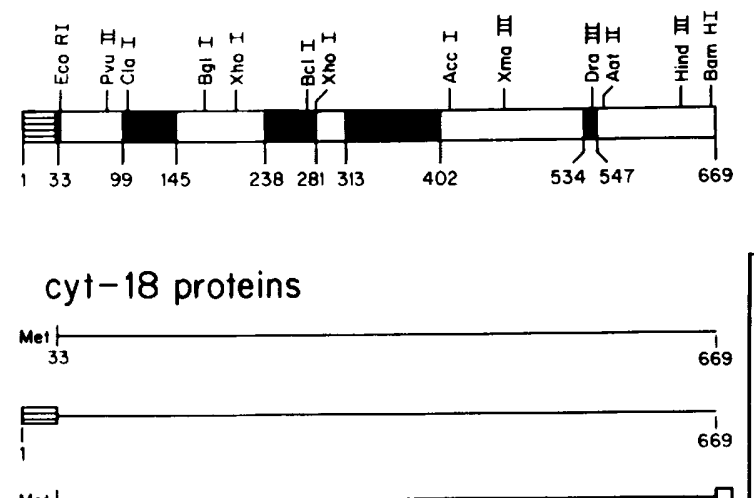

\begin{tabular}{|c|c|c|}
\hline Plasmid & TyrRS & $\underline{\text { Spl }}$ \\
\hline $\begin{array}{l}\text { pEX550 } \\
\text { pEX550A }\end{array}$ & $\stackrel{+}{+}$ & + \\
\hline$p E \times 554$ & + & + \\
\hline pEX511 & + & + \\
\hline pEX521 & + & - \\
\hline DEXX553 & - & - \\
\hline DEX515 & + & + \\
\hline pEX523 & + & + \\
\hline DEX551 & - & \pm \\
\hline pEX571 & + & + \\
\hline pEX558 & - & + \\
\hline pEX573 & + & + \\
\hline pEX562 & + & + \\
\hline pEX561 & - & - \\
\hline pEX575 & - & \pm \\
\hline pEX603 & - & - \\
\hline pEX602 & - & - \\
\hline pEX532 & - & - \\
\hline pEX531 & - & $(-1)$ \\
\hline pEX533 & + & + \\
\hline pEX534 & + & + \\
\hline
\end{tabular}

necessary and sufficient to splice the Neurospora mitochondrial large rRNA intron in vitro. The ability of purified cyt-18 protein to splice the mitochondrial large rRNA intron in vitro implies that it binds directly to intron RNA.

Although the cyt-18 protein is, by itself, sufficient to splice the mitochondrial large rRNA intron in vitro, additional components are required for efficient splicing in vivo. Mutations in two other nuclear genes, cyt-4 and cyt-19, inhibit splicing of the mitochondrial large rRNA intron and other group I introns but do not result in deficiency of cyt-18 protein or splicing activity assayed in vitro (Bertrand et al. 1982; Garriga and Lambowitz 1986; Q. Guo and A. Lambowitz, unpubl.) The cyt-4 mutation may inhibit splicing indirectly by affecting 3 '-end synthesis of the mitochondrial large rRNA (Garriga et al. 1984). The cyt-19 component, which has not yet been identified, may function as part of a complex with the cyt-18 protein or it may act independently on the intron
RNA to stabilize structures that form spontaneously in vitro, so that only the final addition of the protein is required for splicing to occur.

We used in vitro mutagenesis of the $E$. coli synthesized cyt-18 protein to delineate regions that are required for splicing or tyrRS activity. The structural organization of the related bacterial tyrRSs and the $\mathrm{x}$-ray crystal structure of the B. stearothermophilus tyrRS (Fig. 5) appear to be useful guides in interpreting the in vitro mutants, as well as the original cyt-18-1 and cyt-18-2 mutants and the previously described revertants (Cherniack et al. 1990). Compared with the cognate bacterial tyrRSs, the cyt-18 protein has an amino-terminal extension, which presumably targets the protein to mitochondria, and a carboxy-terminal extension of 122 amino acids (downstream of amino acid 547; Fig. 5). The presence of the amino-terminal leader in the pEX554 protein does not strongly affect either splicing or mt tyrRS activities, raising the possibility that these "foreign" activities may be 
Table 1. Tyrosyl adenylation activity of cyt-18 proteins synthesized in E. coli

\begin{tabular}{lcr}
\hline Construct & $\begin{array}{c}\text { Tyrosyl adenylation } \\
\text { (cpm) }\end{array}$ & $\begin{array}{r}\text { TyrRS } \\
\text { (cpm) }\end{array}$ \\
\hline pEX501 & $3,000 \pm 2,100$ & 763 \\
pEX511 (wt) & $14,196 \pm 86$ & 247,590 \\
pEX602 & $27,360 \pm 110$ & 10,043 \\
pEX603 & $24,000 \pm 5,500$ & 2,025 \\
No protein & $570 \pm 130$ & - \\
\hline
\end{tabular}

Derivatives of the cyt-18 protein synthesized in E. coli and partially purified by heparin-Sepharose chromatography $(0.5 \mathrm{M} \mathrm{KCl}$ fractions) were assayed for tyrosyl-adenylation and tyrRS activity. Synthesis of tyrosyl-adenylate was assayed by the binding of ${ }^{3} \mathrm{H}$-labeled tyrosyl-adenylate/protein complex to nitrocellulose filters, as described in Materials and methods. Portions of column fractions used for assays contained $2.7 \mu \mathrm{g}$ of total protein and approximately equal amounts of cyt-18 proteins (pEX511, pEX602, and pEX603), as judged by immunoblots. Data shown are the average of two assays for each sample and are similar to results in repeated experiments.

associated with pre-cyt-18 protein in the Neurospora cytosol. The carboxy-terminal 39 amino acids of the cyt-18 protein can be removed (pEX533) or the carboxyl terminus can be replaced with vector sequences (pEX511) without substantially affecting either splicing or tyrRS activity in vitro. However, it is possible that these carboxy-terminal amino acids have some function in vivo, such as interaction with another protein or larger complex. Deletion of 116 amino acids in pEX531 inhibits both tyrRS and splicing activity.

Mutations in the nucleotide binding fold region have different effects depending on their location. The original cyt-18-1 and cyt-18-2 mutations, which result in temperature-sensitive defects in both splicing and aminoacylation in vivo, affect a conserved Gly residue, which in the B. stearothermophilus tyrRS is a turn residue on the exterior of the nucleotide binding fold (Fig. 5). The cyt-18 mutations may identify a region of the nucleotide binding fold that functions directly in splicing or they may inhibit splicing and tyrRS activities by affecting the conformation of other regions of the protein. In this study, we find that two linker insertion mutations elsewhere in the nucleotide binding fold (pEX571 and pEX573) have no discernible effect on either splicing or tyrRS activity. However, two other mutations (pEX551 and pEX558), which are within the predicted adenylate-binding cleft in a position to interfere directly with binding of tyrosyl adenylate (Fig. 5), inhibit tyrRS activity, but leave some splicing activity. These findings indicate that neither the functional integrity of the ATPbinding site nor the normal catalytic activity of the cyt18 protein is required for splicing activity.

Our results confirm that a small idiosyncratic domain at the amino terminus of the cyt-18 protein is required for splicing, but not tyrRS activity. This domain was identified initially by the clustering of suppressor mutations in partial revertants of the cyt-18-2 mutation that restore splicing, but not tyrRS activity (Cherniack et al. 1990). The suppressor mutations in this region are readily accounted for by the three-dimensional model of Figure 5, which suggests that this amino-terminal domain may adjoin and interact with the region containing the cyt-18-2 mutation, Gly127. In this study we confirmed that a large deletion in this domain (43 amino acids; pEX521) inhibits splicing completely while having relatively little effect on tyrRS activity, including little or no effect on the $K_{\mathrm{m}}$ values for $E$. coli tRNA ${ }^{\mathrm{Tyr}}$ or ATP. These findings are also rationalized by the model, which suggests that the idiosyncratic domain could be deleted without significantly affecting the structure of the nucleotide binding fold or carboxy-terminal domain, which are required for tyrRS activity. The idiosyncratic aminoterminal domain may function directly in binding the intron RNA or it may interact with other regions of the protein that bind the intron RNA. If this region functions in binding the intron, it presumably interacts with RNA sequences or structures that are present in the intron, but not in E. coli tRNA ${ }^{\mathrm{Tyr}}$.

In the previous study, we identified a single partial revertant, R67-10, which has secondary amino acid changes at Asp189 and Thr190 (Cherniack et al. 1990). The three-dimensional model shows that these amino acids are also in proximity to the cyt-18-2 mutation (positions marked by 571 in Fig. 5). However, replacing these amino acids with a single Gly in pEX571 did not substantially affect splicing or tyrRS activity. The second-site suppression in R67-10 could be explained in either of two ways: The entire surface of the cyt-18 protein identified in Figure 5 by pEX521, cyt-18-2, and pEX571 may be required for splicing, with the change in pEX571 being one that is permissible to retain function; or, alternatively, the suppressor mutation in R67-10 may act indirectly by affecting the abnormal structure caused by the cyt-18-2 mutation.

Finally, we find that a number of deletions or linker insertion mutations in the carboxy-terminal region corresponding to the tRNA-binding domain of bacterial tyrRSs inhibit both splicing and tyrRS activity, consistent with the idea that some sequences that function in binding $E$. coli tRNA ${ }^{\mathrm{Tyr}}$ also function in binding the intron RNA. This finding is also consistent with the hypothesis that the protein recognizes a structure or sequence within the intron that resembles the tRNA ${ }^{\text {Tyr }}$ substrate. Interestingly, the pEX575 protein, which has a single amino acid deletion (Asn545) within the short stretch conserved in bacterial and yeast $\mathrm{mt}$ tyrRS, lacks tyrRS activity but has detectable, albeit reduced, splicing activity. The differential effects observed with pEX 575 indicate that some amino acids do not function identically in both processes.

Considered together, our results show that regions required for splicing are distributed throughout the cyt-18 protein and overlap but are not identical to regions required for tyrRS activity. The finding that the normal catalytic activity of the protein is not required for splicing is consistent with the hypothesis that the protein functions primarily by facilitating formation of the cor- 
rect RNA structure. As discussed previously, the involvement of a small amino-terminal idiosyncratic domain, which is not found in $E$. coli or yeast $m$ t tyrRSs, suggests that splicing activity of the Neurospora protein was acquired recently in evolution after the divergence of Neurospora and yeast (Cherniack et al. 1990). However, our results also show that this region must act in concert with other regions of the cyt-18 protein, particularly the putative tRNA-binding domain toward the carboxyl terminus of the protein. By using the $E$. coli expression system, it should be possible to investigate in detail the interaction of cyt-18 protein with the intron RNA and the role of cyt-18 protein in splicing.

\section{Materials and methods}

\section{N. crassa strains}

The $N$. crassa strain used in this study was mutant cyt-4-1 (AEG-193a, Bertrand et al. 1982). Procedures for maintaining the strain, preparing conidia, and growing mycelia in liquid culture were described previously (Davis and de Serres 1970; Bertrand et al. 1982).

\section{E. coli strains}

E. coli strain BL21 (DE3)[plysS], which was used for expression of cyt-18 proteins, contains an IPTG-inducible T7 RNA polymerase gene (Rosenberg et al. 1987). E. coli $\mathrm{K} 12565 \mathrm{cN}$ has a temperature-sensitive mutation in the tyrRS (Bedoulle and Winter 1986; obtained from the University Chemical Laboratory Cambridge, England). AL565(DE3) is $565 \mathrm{cN}$ lysogenized with $\mathrm{T} 7$ bacteriophage DE3.

\section{Recombinant plasmids and phage}

Plasmid p337 contains the cyt-18 gene (3.3-kb BamHI fragment) cloned in Bluescribe vector [pBS|+); Stratagene] (Cherniack et al. 1990). To prepare the cyt-18 gene for expression in E. coli, the 3.3-kb BamHI fragment containing the cyt-18 gene from p337 was inserted into the BamHI site of $\mathrm{M} 13 \mathrm{mp} 18$ and the intron was deleted by oligonucleotide-directed mutagenesis (Kunkel et al. 1987), using the oligonucleotide 5 -ATGTGCTCTTTGGTGCCAGCTGTATCCTTG-3'. The resulting M13 phage, which contains a continuous cyt-18 ORF, is designated mpALM1. This phage was constructed by A. Majumder.

Plasmids plysS and pET3a and bacteriophage DE3, which were used in the bacterial expression strains, were constructed by Rosenberg et al. (1987). pEX501 is a simple derivative of pET3a in which the EcoRI site was disrupted by filling in with Klenow fragment of DNA polymerase I. pEX503 is a derivative of pEX501, which has the palindromic oligonucleotide $5^{\prime}$ TATGCTGCGCAGAATTCTGCGCAGCA-3' inserted in the unique NdeI cloning site. This insert places the first 5 codons of the mature cyt-18 protein (Leu33 to Phe37) in the correct reading frame downstream of the ATG start codon of the vector and introduces a unique EcoRI site, which was used later to insert the remainder of the cyt-18 ORF. pEX503 also lacks the ClaI site of pEX501, which was destroyed by filling in with Klenow fragment.

pEX511 expresses a cognate of the mature form of the cyt-18 protein beginning with Leu33 inserted immediately downtream of the ATG start codon in the expression vector pEX503. To construct this plasmid, pEX503, which already contains the vector ATG codon in-frame with the first 5 amino acids of the cyt-18 ORF (see above), was digested with EcoRI and BamHI. The resulting 4.4-kb EcoRI-BamHI fragment was ligated with two different segment of the cyt-18 gene: a sequenced 200-bp EcoRI-ClaI fragment encompassing the site of the intron deletion from mpALM1, and the $1.7-\mathrm{kb}$ ClaI-BamHI fragment containing the main body of the cyt-18 gene from p337. pEX511 still lacks the final 3 codons of the cyt-18 ORF and instead substitutes 18 codons from vector sequence at the carboxyl terminus.

pEX550 expresses a cognate of the mature form of the cyt-18 protein, including the correct carboxyl terminus. This plasmid was derived from pEX511 by inserting a double-stranded oligonucleotide (top, 5'-GATCCGTATAAGTGGTGACGCGT-3'; bottom, 5'-GATCACGCGTCACCACTTATACG-3') into the BamHI site of pEX511. The correct orientation restores the final 3 codons of the cyt-18 gene and creates an MluI site at the stop codon. pEX550A is the same as pEX550, except that to facilitate in vitro mutagenesis most of the residual te $t^{R}$ gene in the vector was deleted by digestion with NarI and religation, leaving a single NarI site.

pEX554 expresses the full-length cyt-18 ORF, including the amino-terminal mitochondrial targeting sequence. The construction of this plasmid began with M13 phage mpALM1, which contains the full-length cyt-18 ORF. An NdeI site was introduced at the ATG start codon of the cyt-18 ORF by oligonucleotide-directed mutagenesis, using the oligonucleotide $5^{\prime}$ TGTGCGAAGCAGCATATGTGATGTTTGGCT-3' to create mpALM2. The mutagenized region was sequenced, and the 107bp NdeI-EcoRI fragment was used to replace the 14-bp NdeIEcoRI fragment of pEX550, thereby restoring the amino-terminal targeting sequence.

pEX553 is a derivative of pEX550 that has a deletion of $216 \mathrm{bp}$ (72 amino acids) between the two XhoI sites in the cyt-18 ORF.

pEX521 was derived from pEX511 by deleting sequences between the EcoRI site (filled in with Klenow fragment) and the Pvull site of the cyt-18 gene, with the insertion of a NcoI linker (CCCATGGG) to maintain the reading frame. The correct carboxyl terminus of the ORF was restored by inserting a doublestranded oligonucleotide, as described above for pEX550. The pEX521 construction deletes 45 amino acids, but 2 of these are restored in the correct position by the linker. This protein was referred to previously as $\Delta 45$ (Cherniack et al. 1990).

pEX531, pEX532, pEX533, and pEX534 are a series of plasmids that produce cyt-18 proteins having carboxy-terminal truncations. These plasmids were created by inserting a palindromic linker 5'-TGAGTGACTGAATTCAGTCACTCA-3', which contains stop codons in all three reading frames, into pEX511 at the AatII, DraIII, HindIII, and BamHI sites, respectively.

pEX515 and pEX523 are derivatives of pEX511 in which NcoI linkers were inserted into the cyt-18 ORF at the EcoRI and PvuII sites, respectively. In the case of pEX523, it was necessary to restore the reading frame by filling in the NcoI site with Klenow fragment of DNA polymerase I.

pEX551 is a derivative of pEX550 in which a BamHI linker $\left(5^{\prime}\right.$-GCGGATCCGC-3') was inserted into the cyt-18 ORF at the ClaI site.

pEX558, pEX561, and pEX573 are derivatives of pEX550A in which an NcoI linker was inserted into the cyt-18 ORF at the BclI, XmaIII, or downstream XhoI site, respectively. pEX562 has a BamHI linker (10-mer) inserted in the Accl site of the cyt-18 ORF in pEX550A.

pEX571 and pEX575 have 3-bp deletions in the cyt-18 ORF. These plasmids were constructed by digestion of pEX550A with BgII or DraIII, respectively, removal of the 3 ' overhangs using the $3^{\prime} \rightarrow 5^{\prime}$ exonuclease activity of Klenow fragment (Maniatis et al. 1982), and religation. 
pEX602 and pEX603 are derivatives of pEX511, which have extensive carboxy-terminal truncations. To create these plasmids, the 2.2-kb SalI-HindIII fragment, containing the cyt-18 gene from $\mathrm{p} 337$, was recloned in $\mathrm{M} 13 \mathrm{mp} 19$. The resulting $\mathrm{M} 13$ clone, designated $\mathrm{mpWLl}$, was subjected to oligonucleotide-directed mutagenesis to juxtapose a TAA stop codon, normally out-of-frame with the cyt-18 ORF, to the truncation end points. In the case of pEX603, the oligonucleotide 5'-AGCAGGTTGCCGTTAGTCTTTGATGTGCTC-3' was used to delete 449 nucleotides from the cyt-18 gene, placing the TAA codon just after Asp382; for pEX602, the oligonucleotide 5'-AGCAGGTTGCCGTTAAATGGTCATCTGGCC-3' was used to delete $326 \mathrm{nu}$ cleotides of the cyt-18 gene, placing a stop codon just after Ile423. The deletion end points were sequenced, and the plasmids were assembled by replacing the resident $1.6-\mathrm{kb}$ ClaIHindIII fragment from the cyt-18 portion of pEX511 with the corresponding ClaI-HindIII fragments containing the deletion end points from the double-stranded M13 phage DNA.

\section{Expression of cyt-18 protein in $\mathrm{E}$. coli}

Fresh $\mathrm{Amp}^{\mathrm{R}} \mathrm{Cam}^{\mathrm{R}}$ colonies of BL21(DE3)[plysS], transformed with the desired pEX plasmid, were grown overnight at $37^{\circ} \mathrm{C}$ in $3-\mathrm{ml}$ cultures containing LB plus ampicillin $(50 \mu \mathrm{g} / \mathrm{ml})$ and chloramphenicol $(15 \mu \mathrm{g} / \mathrm{ml})$. The overnight cultures were inoculated $(1: 100)$ into $30 \mathrm{ml}$ of N-Z/M9 media in $125-\mathrm{ml}$ Erlenmeyer flasks and incubated with aeration at $37^{\circ} \mathrm{C}$ until $\mathrm{OD}_{595}$ was $0.6-0.8$. The synthesis of $c y t-18$ protein was then induced by the addition of $3 \mathrm{mM}$ IPTG in $15 \mathrm{ml}$ of prewarmed N-Z/M9 media and continued incubation for $1 \mathrm{hr}$ at $37^{\circ} \mathrm{C}$. For the temperature-sensitive strain AL565(DE3), bacteria were cultured and induced at $30^{\circ} \mathrm{C}$.

Prior to harvesting, each induced culture was diluted with $120 \mathrm{ml}$ of ice-cold TES buffer [10 mM Tris- $\mathrm{HCl}(\mathrm{pH} 8.0), 1 \mathrm{~mm}$ EDTA, $10 \mathrm{~mm} \mathrm{NaCl}$. The cells were then pelleted by centrifugation in a Beckman JA-14 rotor at $2500 \mathrm{~g}$ for $10 \mathrm{~min}$. Pelleted cells were resuspended by brief vortexing with $400 \mu \mathrm{l}$ of TES buffer containing lysozyme $(10-12 \mathrm{mg} / \mathrm{ml})$ and incubated on ice for $30 \mathrm{~min}$, followed by addition of $1.2 \mathrm{ml}$ of lysis II buffer [20 mM Tris $\mathrm{HCl}$ (pH 8.0), $1.5 \mathrm{~mm}$ 2-mercaptoethanol, 1 mM PMSF, $1 \%$ Triton X-100] with gentle swirling. For small-scale purifications, the cell suspension was then aliquoted into five Eppendorf tubes, frozen immediately on dry ice, and stored at $-70^{\circ} \mathrm{C}$ until used. For medium-scale purifications, cells were transferred to a single 40-ml Oak Ridge tube prior to freezing.

To prepare soluble fractions for chromatography in smallscale DEAE-Sephacel or heparin-Sepharose columns, cells frozen in lysis II buffer were thawed by gentle swirling at $0^{\circ} \mathrm{C}$ to $4^{\circ} \mathrm{C}$ for 5-10 min until lysis was evident. Following addition of $150 \mu \mathrm{l}$ of TC buffer [ $50 \mathrm{~mm}$ Tris- $\mathrm{HCl}(\mathrm{pH} 8.3), 3 \mathrm{~mm} \mathrm{CaCl}$ ] plus 100 units of micrococcal nuclease, the solution was incubated on ice for $10 \mathrm{~min}$, until it was no longer highly viscous. It was then spun in an Eppendorf microcentrifuge at 14,000 $\mathrm{g}$ for $5 \mathrm{~min}$ to pellet cellular debris and insoluble protein.

Preparation of soluble fractions for medium-scale purification of the cyt-18 protein was essentially the same as that described above, except the larger volume of cells required the addition of $1.2 \mathrm{ml}$ of TC buffer along with 500 units of micrococcal nuclease. Insoluble material was removed by centrifugation in a Beckman JA-17 rotor at $14,000 \mathrm{~g}$ for $10 \mathrm{~min}$ at $0-4^{\circ} \mathrm{C}$.

\section{Small-scale heparin-Sepharose chromatography}

Chromatography of $E$. coli-synthesized cyt-18 proteins in smallscale heparin-Sepharose columns was essentially as described for cyt-18 protein from mitochondria (Majumder et al. 1989), except that $1 \mathrm{mM}$ PMSF was included in all column buffers. Chromatography was at $4^{\circ} \mathrm{C}$ in $0.7 \times 4-\mathrm{cm}$ glass columns with bed volumes of $1.5 \mathrm{ml}$. The columns were loaded with $400-600$ $\mu \mathrm{l}$ of $E$. coli-soluble protein fraction containing 1-3 mg of protein and were eluted with a step gradient of $0,0.25$, and $0.5 \mathrm{M}$ $\mathrm{KCl}$ in TEDG buffer [ $20 \mathrm{~mm}$ Tris- $\mathrm{HCl}$ ( $\mathrm{pH} 7.5), 1 \mathrm{~mm}$ EDTA, 0.5 mM DTT, $1 \mathrm{mM}$ PMSF, 10\% glycerol]. As found previously for the mitochondrial cyt-18 protein (Majumder et al. 1989), the $E$. coli-synthesized cyt-18 protein was present in both 0 and $0.5 \mathrm{M}$ $\mathrm{KCl}$ fractions. Endogenous $E$. coli tyrRS was found only in the $0.25 \mathrm{M} \mathrm{KCl}$ fractions, as judged by assays of tyrRS activity and by immunoblots probed with anti-E. coli tyrRS antibody. The $0.5 \mathrm{M} \mathrm{KCl}$ fractions, which contained $\geqslant 50 \%$ cyt- 18 protein, were used for analysis of splicing and tyrRS activites of mutant cyt-18 proteins.

\section{Medium-scale purification of cyt-18 protein from $\mathrm{E}$. coli}

For medium-scale purification, E. coli soluble protein fractions from eight pooled lysates, prepared as described above, were loaded onto a $1.5 \times 20-\mathrm{cm}$ glass column containing $30 \mathrm{ml}$ of DEAE-Sephacel equilibrated with PEDG buffer $\left[20 \mathrm{mM} \mathrm{KPO}_{4}\right.$ (pH 7.6), 1 mM EDTA, 0.5 mM DTT, 1 mM PMSF, 10\% glycerol]. After loading, the column was washed successively with $75 \mathrm{ml}$ of PEDG, $30 \mathrm{ml}$ of $0.1 \mathrm{M} \mathrm{KCl}$ in PEDG, and $30 \mathrm{ml}$ of $0.25 \mathrm{M} \mathrm{KCl}$ in PEDG. The flow rate was $\sim 300 \mu \mathrm{l} / \mathrm{min}$. Fractions $(5 \mathrm{ml})$ were collected for the 0 and $0.1 \mathrm{M} \mathrm{KCl}$ washes, and $3-\mathrm{ml}$ fractions were collected thereafter. The major peak of cyt-18 protein, identified by dot blots, eluted just before the large change in conductivity at the $0.25 \mathrm{M} \mathrm{KCl}$ salt front.

In the next step, the pooled peak fractions containing cyt-18 protein from the DEAE-Sephacel column $(6-11 \mathrm{ml}$, containing up to $3 \mathrm{mg}$ of protein) were desalted by gel filtration through Sephadex G-75-120 (Pharmacia). Gel filtration was in a $1.5 \times 20$-cm glass column containing $28 \mathrm{ml}$ of Sephadex G-75120 equilibrated with TEDG buffer. The column was eluted with $30 \mathrm{ml}$ of TEDG, $1-\mathrm{ml}$ fractions were collected, and the fractions containing most of the excluded peak $(\sim 18 \mathrm{ml})$ were pooled for heparin-Sepharose chromatography.

Finally, heparin-Sepharose chromatography was carried out in a $1.5 \times 5-\mathrm{cm}$ glass column containing $5 \mathrm{ml}$ of heparin-Sepharose CL6B (Pharmacia) equilibrated with TEDG buffer (see above). After loading, the column was washed successively with $20 \mathrm{ml}$ of TEDG, $0.25 \mathrm{M} \mathrm{KCl}$ in TEDG, and $0.5 \mathrm{M} \mathrm{KCl}$ in TEDG, and $1-\mathrm{ml}$ fractions were collected. At this stage of purification, active cyt-18 protein eluted from the heparin-Sepharose column predominantly at $0.5 \mathrm{M} \mathrm{KCl}$, with only trace amounts in flowthrough fractions. Residual E. coli tyrRS was in the $0.25 \mathrm{M}$ $\mathrm{KCl}$ fraction.

Preparation of cyt-18 protein from N. crassa mitochondria

cyt-18 protein was partially purified from mt RNP preparations of Neurospora nuclear mutant cyt-4-1, which has elevated levels of cyt-18 protein, by heparin-Sepharose chromatography (Majumder et al. 1989). The columns were eluted with a step gradient, and $0.5 \mathrm{M} \mathrm{KCl}$ fractions, which contain cyt-18 protein, were used for assays of splicing and tyrRS activities.

\section{Splicing assays}

Splicing was assayed as described previously, using a 698-nucleotide in vitro transcript containing a 583-nucleotide derivative of the mitochondrial large rRNA intron that is not selfsplicing (Guo et al. 1991). This transcipt was synthesized from 
plasmid pHX9422 linearized with BanI, using bacteriophage T3 RNA polymerase (GIBCO, BRL). Splicing reactions were carried out in $20 \mu \mathrm{l}$ of solution containing $1 \mu \mathrm{g}$ of in vitro transcript, 4 $\mu l$ of protein preparation, $100 \mathrm{mM} \mathrm{KCl}, 5 \mathrm{mM} \mathrm{MgCl}, 20 \mathrm{~mm}$ Tris- $\mathrm{HCl}(\mathrm{pH} 7.5), 5 \mathrm{~mm}$ DTT, $40 \mu \mathrm{Ci}$ of $\left[\alpha^{-32} \mathrm{P}\right] \mathrm{GTP}(0.6 \mu \mathrm{M}$; $3000 \mathrm{Ci} / \mathrm{mmole} ; \mathrm{NEN}$ ), and 40 units of RNasin (Promega) or 0.25 units of Inhibit-ACE (5 Prime $\rightarrow 3$ Prime, Inc.). Reactions were initiated by the addition of the protein preparation, incubated for $15 \mathrm{~min}$ or $30 \mathrm{~min}$ at $37^{\circ} \mathrm{C}$, and terminated by the addition of 6.5 volumes of $20 \mathrm{~mm}$ Tris- $\mathrm{HCl}(\mathrm{pH} 7.5)$ and $50 \mathrm{~mm}$ EDTA, followed by phenol extraction and ethanol precipitation in the presence of $2 \mathrm{M}$ ammonium acetate. Splicing products were analyzed by electrophoresis in $4 \%$ polyacrylamide $/ 8 \mathrm{M}$ urea gels (unless otherwise specified), followed by autoradiography. In some experiments, splicing was assayed by using ${ }^{32} \mathrm{p}$ labeled in vitro transcripts, which were labeled internally by adding $50 \mu \mathrm{Ci}$ of $\left[\alpha^{-32} \mathrm{P}\right] \mathrm{GTP}$ to $200 \mu \mathrm{l}$ of the standard transcription mixture containing $500 \mu \mathrm{M}$ of each unlabeled NTP. ${ }^{32} \mathrm{P}$ Labeled in vitro transcripts were phenol extracted and purified by using a Sephadex G-50 spun column (Maniatis et al. 1982). Splicing assays were performed as described above, using $5 \mathrm{nCi}$ of the ${ }^{32} \mathrm{P}$-labeled in vitro transcript plus $500 \mu \mathrm{M}$ GTP or guanosine (see below). Reactions were terminated by the addition of 4 volumes of $80 \%$ formamide $/ 1 \%$ xylene cyanol, and products were incubated at $85^{\circ} \mathrm{C}$ for $5 \mathrm{~min}$, prior to loading onto a gel. To determine $K_{\mathrm{m}}$ values for guanosine or GTP, guanosine concentrations were varied from 1 to $100 \mu \mathrm{M}$ and GTP concentrations were varied from 10 to $400 \mu \mathrm{M}$. $K_{\mathrm{m}}$ values were determined by Eadie-Hofstee plots; values indicated in Results are the average of at least two determinations.

\section{TyrRS assays}

TyrRS activity in lysates or column fractions was assayed by using $E$. coli $\mathrm{tRNA}_{2}{ }^{\text {Tyr }}$ substrate (Subriden RNA), as described by Majumder et al. (1989). For both $E$. coli-synthesized and mitochondrial cyt-18 protein, tyrRS activity is less stable than splicing activity, so that tyrRS assays were carried out with freshly isolated protein. To determine the $K_{\mathrm{m}}$ values for the tRNA, $0.1-20 \mu \mathrm{g}$ of tRNA was used per $20-\mu \mathrm{l}$ reaction. The $K_{\mathrm{m}}$ values for ATP were determined by varying ATP concentrations from 0.1 to $2 \mathrm{mM}$, with $K_{\mathrm{m}}$ values obtained from Eadie-Hofstee plots.

\section{Tyrosyl-adenylation assay}

Tyrosyl-adenylation was assayed by incorporation of $\left[{ }^{3} \mathrm{H}\right]$ tyrosine into protein-bound tyrosyl-adenylate (Leatherbarrow and Fersht 1987). Assays were carried out in $50 \mu \mathrm{l}$ of reaction mixture containing $10 \mu \mathrm{l}$ of cyt-18 protein preparation. The protein preparations were adjusted so that all reactions used 2.7 $\mu \mathrm{g}$ of protein and the final $\mathrm{KCl}$ concentration in reaction medium was $100 \mathrm{~mm}$. The reaction medium also contained 12.5 $\mu \mathrm{Ci}$ of $\mathrm{L}-\left[3-, 5^{3} \mathrm{H}\right]$ tyrosine $(54 \mathrm{Ci} / \mathrm{mmole}$; Amersham) diluted to a final concentration of $4.6 \mu \mathrm{M}$ L-tyrosine, $5 \mathrm{~mm} \mathrm{ATP}, 10 \mathrm{mM}$ $\mathrm{MgCl}_{2}, 144 \mathrm{~mm}$ Tris- $\mathrm{HCl}$ (pH 7.8), $14 \mathrm{~mm}$ 2-mercaptoethanol, $0.1 \mathrm{mM}$ PMSF, and 0.1 unit of pyrophosphatase Boehringer Mannheim). Reactions were incubated for $40 \mathrm{~min}$ at $25^{\circ} \mathrm{C}$, after which protein-bound tyrosyl-adenylate was collected on a nitrocellulose filter. The filter was washed three times with $6 \mathrm{ml}$ of the ice-cold reaction buffer, and radioactivity was determined by liquid scintillation counting, using Ready Protein ${ }^{+}$liquid scintillation cocktail (Beckman Instruments, Inc.). The amount of cyt-18 protein was determined by probing immunoblots with anti-cyt-18 antibody (see below).

\section{SDS-PAGE and immunoblotting}

Procedures for SDS-PAGE and immunochemical analysis were described in detail previously (Majumder et al. 1989; Cherniack et al. 1990). SDS-PAGE was carried out by the method of Laemmli (1970), using a $3 \%$ stacking gel and a $10 \%$ separating gel Gels were run in a mini-PROTEAN II apparatus $10.75-\mathrm{mm} \times 5$ $\mathrm{cm} \times 8-\mathrm{cm}$ slab gels; Bio-Rad Laboratories/ at 100-150 V, until the bromphenol blue dye marker reached the bottom of the gel. For immunoblot analysis, proteins separated by SDS-PAGE were electroblotted to nitrocellulose, using a polyblot apparatus (American Bionetics), and probed with a 1:1000 dilution of anti-cyt-18 antibody preparation C18-2, which is directed against a $\operatorname{trp} E-c y t-18$ fusion protein containing amino acids 103-563 of the cyt-18 protein. For proteins having carboxy-terminal truncations (i.e., 602, 532, and 531), immunoblots were probed with antibody preparation $\mathrm{C18}-1$, which is directed against amino acids $36-82$ at the amino terminus of the cyt-18 protein. To detect endogenous $E$. coli tyrRS in column fractions, immunoblots were probed with 1:1000 dilutions of antibody against $E$. coli tyrRS obtained from Edwards and Schimmel (1987). For dot blots, $1.5 \mu \mathrm{l}$ of column fraction was dotted onto nitrocellulose, dried, and developed with anti-cyt-18 antibody (Majumder et al. 1989).

\section{Protein sequencing}

To determine amino-terminal amino acid sequence, cyt-18 protein was partially purified from mitochondria of $N$. crassa cyt4-1 by heparin-Sepharose chromatography. The final $0.5 \mathrm{M} \mathrm{KCl}$ heparin-Sepharose fraction, containing $\sim 35 \mu \mathrm{g}$ of protein, was precipitated with 4 volumes of acetone. After washing with acetone, the pellet was resuspended in $50 \mu \mathrm{l}$ of SDS-gel sample buffer, and SDS-PAGE was carried out as described above, except that the gel thickness was $1.5 \mathrm{~mm}$ and the gel was run until a $30-\mathrm{kD}$ prestained protein marker reached the bottom. Following electrophoresis, the gel was electroblotted onto a polyvinylidene difluoride (PVDF) membrane, as described (Matsudaira 1987). The membrane was stained with Coomassie brilliant blue, and the band containing cyt-18 protein was identified by the immunoblotting of a parallel lane. Ten amino acids of amino-terminal sequence were determined, by an Applied Biosystems model $470 \mathrm{~A}$ gas-phase sequencer interfaced to a model 120A PTA amino acid analyzer.

The amino-terminal sequence of cyt-18 protein synthesized in $E$. coli was determined by the same procedure, by using pEX550 protein purified as in Figure 3, with $20 \mu \mathrm{g}$ of pEX550 protein preparation loaded onto the SDS-polyacrylamide gel.

\section{Protein determination}

Protein concentrations were determined by the method of Bradford (1976), using a Bio-Rad assay kit.

\section{Acknowledgments}

We thank Ms. Julie Wilkinson for technical assistance in the early stages of work, Dr. Arun Majumder for the construction of bacteriophage mpALM1 and mpALM2, and Qingbin Guo for the pEX550 protein preparation in Figure 3. Synthesis of oligonucleotides and amino-terminal protein sequencing were performed by the Ohio State Biochemical Instrumentation Center. J.D.K. was supported by a National Institutes of Health postdoctoral fellowship (F32 GM13504), and G.M. was supported by a postdoctoral fellowship from the Deutsche Forschungsgemein- 
schaft. This work was supported by National Institutes of Health grant GM37951.

The publication costs of this article were defrayed in part by payment of page charges. This article must therefore be hereby marked "advertisement" in accordance with 18 USC section 1734 solely to indicate this fact.

\section{References}

Akins, R.A. and A.M. Lambowitz. 1987. A protein required for splicing group I introns in Neurospora mitochondria is mitochondrial tyrosyl-tRNA synthetase or a derivative thereof. Cell 50: 331-345.

Bedoulle, H. and G. Winter. 1986. A model of synthetase/transfer RNA interaction as deduced by protein engineering. $\mathrm{Na}$ ture 320: 371-373.

Bertrand, H., P. Bridge, R.A. Collins, G. Garriga, and A.M. Lambowitz. 1982. RNA splicing in Neurospora mitochondria. Characterization of new nuclear mutants with defects in splicing the mitochondrial large rRNA. Cell 29: 517-526.

Bradford, M.M. 1976. A rapid and sensitive method for the quantitation of microgram quantities of protein utilizing the principle of protein-dye binding. Anal. Biochem. 72: 248254.

Brick, P., T.N. Bhat, and D.M. Blow. 1989. Structure of tyrosyltRNA synthetase refined at $2.3 \AA$ resolution. Interaction of the enzyme with tyrosyl adenylate intermediate. J. Mol. Biol. 208: 83-98.

Cherniack, A.D., G. Garriga, J.D. Kittle, R.A. Akins, and A.M. Lambowitz. 1990. Function of Neurospora mitochondrial tyrosyl-tRNA synthetase in RNA splicing requires an idiosyncratic domain not found in other synthetases. Cell 62: 745755.

Collins, R.A. and A.M. Lambowitz. 1985. RNA splicing in Neurospora mitochondria. Defective splicing of mitochondrial mRNA precursors in the nuclear mutant cyt-18-1. /. Mol. Biol.184: 413-428.

Davis, R.H. and F.J. deSerres. 1970. Genetic and microbiological research techniques for Neurospora crassa. Methods Enzymol. 17A: 79-143.

Edwards, H. and P. Schimmel. 1987. An E. coli aminoacyl synthetase can substitute for yeast mitochondrial enzyme function in vivo. Cell 51: 643-649.

Garriga, G. and A.M. Lambowitz. 1984. RNA splicing in Neurospora mitochondria. Self-splicing of a mitochondrial intron in vitro. Cell 39: 631-641.

_ 1986. Protein-dependent splicing of a group I intron in ribonucleoprotein particles and soluble fractions. Cell 46: 669-680.

Garriga, G., H. Bertrand, and A.M. Lambowitz. 1984. RNA splicing in Neurospora mitochondria: Nuclear mutants defective in both splicing and $3^{\prime}$ end synthesis of the large rRNA. Cell 36: 623-634.

Guo, Q., R.A. Akins, G. Garriga, and A.M. Lambowitz. 1991. Structural analysis of the Neurospora mitochondrial large rRNA intron and construction of a mini-intron that shows protein dependent splicing. J. Biol. Chem. 266: 1809-1819.

Kunkel, T.A., J.D. Roberts, and R.A. Zakour. 1987. Rapid and efficient site-specific mutagenesis without phenotypic selection. Methods Enzymol. 154: 367-382.

Laemmli, U.K. 1970. Cleavage of structural proteins during assembly of the head of the bacteriophage T4. Nature 227: 680-685.

Lambowitz, A.M. and P.S. Perlman. 1990. Involvement of aminoacyl-tRNA synthetases and other proteins in splicing of group I and II introns. Trends Biochem. Sci. 15: 440-444.
Leatherbarrow, R.J. and A.R. Fersht. 1987. Investigation of transition-state stabilization by residues histidine- 45 and threonine-40 in the tyrosyl-tRNA synthetase. Biochemistry 26: 8524-8528.

Majumder, A.L., R.A. Akins, J.G. Wilkinson, R.L. Kelley, A.J. Snook, and A.M. Lambowitz. 1989. Involvement of tyrosyltRNA synthetase in splicing of group I introns in Neurospora crassa mitochondria. Biochemical and immunochemical analysis of splicing activity. Mol. Cell Biol. 9: 2089-2104.

Maniatis, T., E. F. Fritsch, and J. Sambrook. 1982. Molecular cloning: A laboratory manual. Cold Spring Harbor Laboratory, Cold Spring Harbor, New York.

Mannella, C.A., R.A. Collins, M.R. Green, and A.M. Lambowitz. 1979. Defective splicing of mitochondrial rRNA in cytochrome-deficient nuclear mutants of Neurospora crassa. Proc. Natl. Acad. Sci. 76: 2635-2639.

Matsudaira, P. 1987. Sequence from picomolar quantities of proteins electroblotted onto polyvinylidene difluoride membranes. J. Biol. Chem. 262: 10035-10038.

Rosenberg, A.H., B.N. Laden, C. Dao-shan, L. Shu-Wha, J.J. Dunn, and F.W. Studier. 1987. Vectors for selective expression of cloned DNAs by T7 RNA polymerase. Gene 56: 125-135.

Schimmel, P. 1987. Aminoacyl tRNA synthetases: General scheme of structure-function relationships in the polypeptides and recognition of transfer RNAs. Annu. Rev. Biochem. 56: 125-158.

von Heijne, G., J. Steppuhn, and R.G. Herrmann. 1989. Domain structure of mitochondrial and chloroplast targeting peptides. Eur. J. Biochem. 180: 535-545.

Waye, M.M.Y., G. Winter, A.J. Wilkinson, and A.R. Fersht. 1983. Deletion mutagenesis using an "M13 splint": The Nterminal structural domain of tyrosyl-tRNA synthetase $(B$. stearothermophilus) catalyses the formation of tyrosyl adenylate. EMBO I. 10: 1827-1829.

Winter, G., G.L.E. Koch, B.S. Hartley, and D.G. Barker. 1983. The amino acid sequence of the tyrosyl-tRNA synthetase from Bacillus stearothermophilus. Eur. J. Biochem. 132: 383-387. 


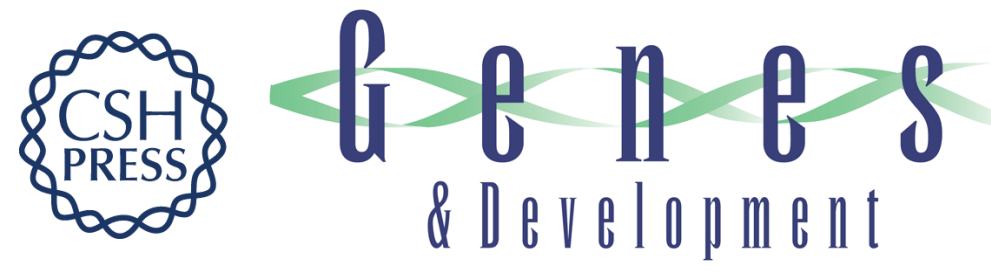

\section{The Neurospora mitochondrial tyrosyl-tRNA synthetase is sufficient for group I intron splicing in vitro and uses the carboxy-terminal tRNA-binding domain along with other regions.}

J D Kittle, G Mohr, J A Gianelos, et al.

Genes Dev. 1991, 5:

Access the most recent version at doi:10.1101/gad.5.6.1009

References This article cites 25 articles, 4 of which can be accessed free at:

http://genesdev.cshlp.org/content/5/6/1009.full.html\#ref-list-1

License

Email Alerting Service

Receive free email alerts when new articles cite this article - sign up in the box at the top right corner of the article or click here.

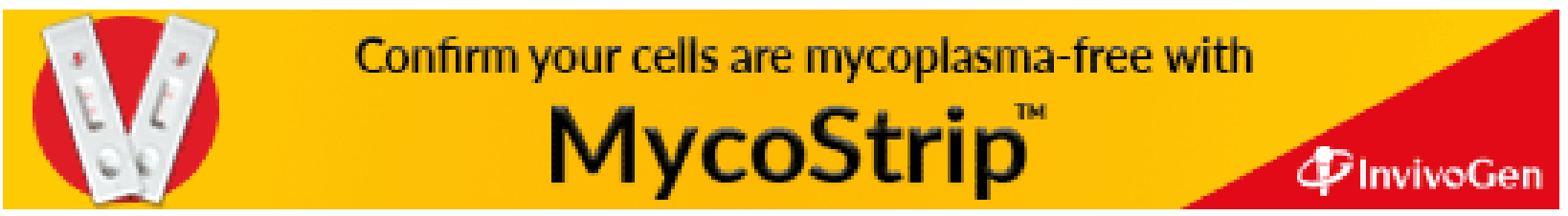

